\title{
CrystEngComm
}

Check for updates

Cite this: CrystEngComm, 2021, 23, 8451

Received 1st September 2021,

Accepted 7th November 2021

DOI: $10.1039 /$ d1ce01180d

rsc.li/crystengcomm

\section{Laser-induced nucleation promotes crystal growth of anhydrous sodium bromide $\uparrow$}

\author{
Eleanor R. Barber, ${ }^{a}$ Martin R. Ward, (iD ${ }^{b}$ \\ Andrew D. Ward ${ }^{C}$ and Andrew J. Alexander (D)*a
}

\begin{abstract}
We report on a study of crystal hydrate formation in supersaturated aqueous sodium bromide using different methods to induce nucleation: mechanical shock-induced nucleation (MSIN), nucleation by ultrasound (sonocrystallization), non-photochemical laser-induced nucleation (NPLIN) and laser-trapping nucleation. The most stable crystal form at room temperature is known to be sodium bromide dihydrate $(\mathrm{DH})$ and this form was favoured (>95\%) through spontaneous nucleation or mechanical shock. Sonocrystallization favoured DH crystals (74\%). Remarkably both laser-induced nucleation methods showed a strong preference (>90\%) for anhydrous ( $\mathrm{AH}$ ) crystals. The nucleation mechanisms are discussed with reference to the solution-solid phase diagram. For laser-trapping nucleation, the results are consistent with previous studies showing that nucleation is preceded by formation of a localised volume of increased solute concentration. The common mechanistic feature linking sonocrystallization, MSIN and NPLIN is cavitation. The preference for $\mathrm{AH}$ sodium bromide suggests that nanosecond laser pulses produce cavitation events with more thermal energy compared to the other methods. The results demonstrate the value of laser-induced nucleation in controlling crystal hydrate growth and provide new understanding of the nucleation mechanisms.
\end{abstract}

\section{Introduction}

The nucleation of crystals from a solution or melt is a fundamental process that is of huge scientific and industrial importance, but the underlying mechanisms remain poorly understood. A subject of ongoing interest, particularly in the pharmaceutical industry, is selective formation of polymorphs, co-crystals or solvates. ${ }^{1}$ Different solid forms have different physicochemical properties such as solubility, dissolution rate and stability. ${ }^{2}$ Therefore, where a full characterization of such properties is required, e.g., for active pharmaceutical ingredients, obtaining the correct form is crucial. Polymorph control has been achieved traditionally through optimizing the solvent, supersaturation and temperature; $;^{3-7}$ or by the addition of seed crystals or additives that modify growth at the crystal faces of specific

\footnotetext{
${ }^{a}$ School of Chemistry, University of Edinburgh, David Brewster Road, Edinburgh, EH9 3JJ, UK. E-mail: andrew.alexander@ed.ac.uk

${ }^{b}$ Strathclyde Institute of Pharmacy \& Biomedical Sciences (SIPBS), University of Strathclyde, 161 Cathedral Street, Glasgow, G4 ORE, UK

${ }^{c}$ Central Laser Facility, Research Complex at Harwell, STFC Rutherford Appleton Laboratory, Harwell Oxford, Didcot, OX11 OQX, UK

$\dagger$ Electronic supplementary information (ESI) available. See DOI: 10.1039/ d1ce01180d
}

polymorphs. ${ }^{8,9}$ External effects such as an applied electric field, or ultrasonic or optical irradiation can also influence polymorph and solvate formation. ${ }^{10-15}$

Non-photochemical laser-induced nucleation (NPLIN) is a technique in which a new phase is formed by the exposure of a metastable system to pulses of laser light. The phenomenon was first observed in supersaturated solutions of urea, ${ }^{16}$ and has since been observed in a diverse range of systems including solutions of simple salts $;^{17-22}$ proteins $;^{23,24}$ small molecules in various solvents; ${ }^{13,25-33}$ and onecomponent systems. ${ }^{34,35}$ NPLIN typically utilises millijoule, unfocused, nanosecond laser pulses in the visible or near-IR region of the electromagnetic spectrum at a wavelength that is not absorbed by the sample. Nucleation of carbon dioxide gas bubbles has also been reported. ${ }^{36,37}$

A particularly remarkable result of NPLIN is the ability to control the polymorph of crystals through the polarization of the laser light used for nucleation. ${ }^{13,25}$ This is known as polarization switching. Circularly polarized (CP) light was found to produce the $\alpha$ polymorph of glycine, which is the form obtained by spontaneous nucleation, while linearly polarized (LP) light produced the $\gamma$ polymorph, which is the thermodynamically stable form at room temperature. Polarization switching for glycine occurs only within a narrow window of supersaturation and temperature, and it has been found that switching is difficult to reproduce. ${ }^{27,30,33,38,39}$ 
Polarization effects have also been observed in NPLIN of Lhistidine, ${ }^{26}$ carbamazepine $^{28}$ and sulfathiazole. ${ }^{29}$

The mechanisms of NPLIN are not fully understood. Mechanisms have been proposed based on the optical Kerr effect and the response of solute clusters in solution to an electric field. ${ }^{16,17}$ More recently, laser heating of nanoparticle impurities in the solution, resulting in the formation of vapour cavities, has been proposed as a mechanism that could account for a number of previously unexplained observations. $^{20,36,37}$ For more details see, for example, a recent review by Alexander and Camp. ${ }^{40}$

Polymorph and solvate control have been demonstrated by laser-induced nucleation (LIN) using different light sources. Using focused femtosecond laser pulses, where sufficient power can be delivered to the system for optical breakdown and laser-induced cavitation, selective formation of metastable polymorphs of indomethacin and aspirin were demonstrated by Maruyama and co-workers. ${ }^{41,42}$ Wang et al. also succeeded in increasing the percentage of metastable forms II and III of paracetamol from less than $10 \%$ to more than $40 \%$ using focused femtosecond pulses. ${ }^{43}$ A versatile technique is laser-trapping crystallization, as developed by Masuhara, Sugiyama and co-workers, in which a continuouswave (CW) laser beam is focused at a solution-air interface. ${ }^{44}$ Crystallization occurs via the localization of solute clusters in the focal region, leading to an increased supersaturation. In glycine $/ \mathrm{D}_{2} \mathrm{O}$ solutions, the favoured polymorph was dependent on the concentration, temperature, laser power, and polarization. ${ }^{14,45}$ The polarization switching was explained in terms of the efficiency of trapping of $\alpha$ and $\gamma$-glycine precursor clusters with CP and LP light, as well as conversion from $\alpha$ to $\gamma$ at high concentrations. More recently, control of hydrate formation in $\mathrm{L}$-phenylalanine has been achieved using trapping with a CW-laser beam, or with trains of femtosecond pulses. ${ }^{15,46,47}$

The aim of the present work was to investigate hydrate formation in a simple inorganic salt system using NPLIN. Sodium bromide was selected as a good candidate: an aqueous supersaturated solution under ambient pressure conditions can yield either dihydrate $(\mathrm{DH})$ or anhydrous $(\mathrm{AH})$ crystals. NPLIN was tested at different points on the solutesolvent phase diagram and the resulting crystals were characterised. The results were compared to mechanical shock-induced nucleation (MSIN), sonocrystallization and laser trapping. The results show the ability to control hydrate crystal formation by laser-induced nucleation, and reveal new features of the underlying mechanism.

\section{Experimental methods}

Anhydrous sodium bromide (Sigma Aldrich, ReagentPlus, $\geq 99 \%)$ and ultrapure water $(18.2 \mathrm{M} \Omega \mathrm{cm})$ were used to prepare concentrated solutions of aqueous sodium bromide. In the present work, concentrations $(C)$ are expressed as moles of anhydrous salt per $\mathrm{kg}$ of solvent. Stock solutions with concentrations of 10.0, 10.9 and $11.5 \mathrm{~mol} \mathrm{~kg}^{-1}$ were prepared and held in a temperature-controlled oven $(T=75-$ $95{ }^{\circ} \mathrm{C}$ ) for two days to ensure dissolution. The warm solutions were then transferred to pre-heated glass sample vials $(\sim 5$ $\mathrm{mL}$ ). The vials were sealed and reheated to dissolve any spontaneously formed crystals. The solubility of sodium bromide was determined by fitting tabulated experimental data, and the resulting saturation concentrations $\left(C_{\text {sat }}\right)$ were used to calculate supersaturations $\left(S=C / C_{\text {sat }}\right) \cdot{ }^{48,49}$ The solution conditions are summarized in Fig. 1 (see ESI $\uparrow$ for more details). Supersaturation was in the range 1.01 to 1.29. In terms of Fig. 1, the height of the point above the solubility curve, either the AH curve or the $\mathrm{DH}$ curve, is a measure of supersaturation with respect to that solid form. $\mathrm{DH}$ is the most stable crystal form below the transition temperature of $51{ }^{\circ} \mathrm{C} .{ }^{48,49}$ The dashed curve in Fig. 1 represents extrapolation of the $\mathrm{AH}$ solubility curve data to lower temperatures. We justify this extrapolation based on the analogous sodium-acetate hydrate system, for which solubility data exist in this region below the transition temperature $\left(58^{\circ} \mathrm{C}\right) .{ }^{50}$

The occurrence of NPLIN in sodium bromide solutions was established by counting the number of samples nucleated after exposure to single laser pulses. A set of sample solutions at $11.5 \mathrm{~mol} \mathrm{~kg}^{-1}$ were cooled to either 60 , 55,50 or $45^{\circ} \mathrm{C}$ in a water bath $\left( \pm 1^{\circ} \mathrm{C}\right)$. These temperatures were chosen to explore the transition region around $51{ }^{\circ} \mathrm{C}$ while minimising spontaneous nucleation. After cooling for one hour, each sample was checked for spontaneously formed crystals. Samples which had not nucleated were

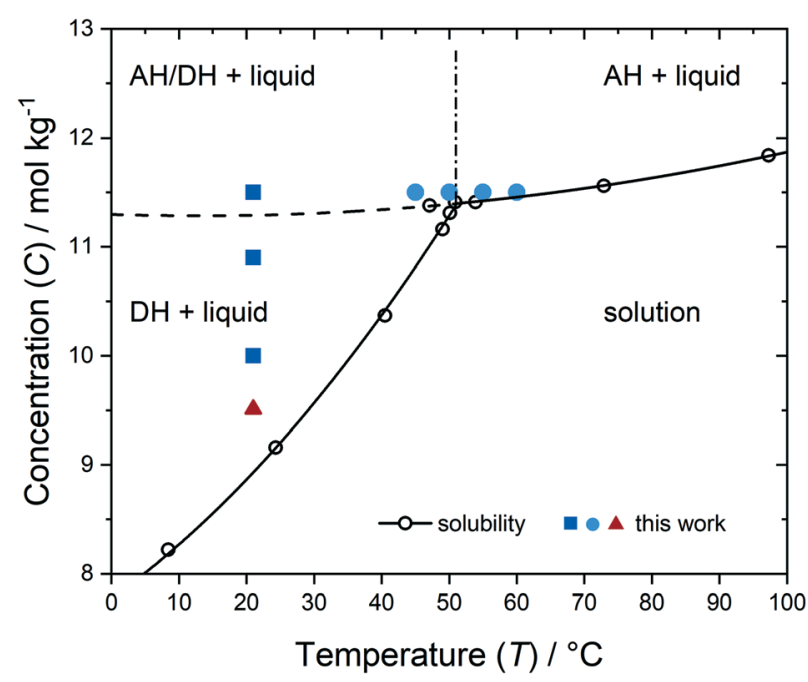

Fig. 1 Phase diagram based on solubility data for $\mathrm{NaBr}+\mathrm{H}_{2} \mathrm{O}$ (open circles). ${ }^{49}$ The most-stable equilibrium solid form in contact with the liquid solution is indicated on the plot $(\mathrm{AH}=$ anhydrous; $\mathrm{DH}=$ dihydrate). The solid curves represent quadratic model fits to the solubility data. The dashed curve represents an extrapolation to low $T$ of the fit of $\mathrm{AH}$ data above the transition temperature $\left(51^{\circ} \mathrm{C}\right)$. The vertical line (dot-dash) is simply to guide the eye at the transition temperature. The experimental conditions in the present work are represented as solid symbols. Note that the laser trapping experiments (solid triangle) were conducted with $\mathrm{NaBr}+\mathrm{D}_{2} \mathrm{O}$, but the phase diagram is qualitatively similar to the one shown. 
placed in a temperature-controlled sample holder and exposed to a single pulse of laser light $(532 \mathrm{~nm})$ with an incident energy density of $1.0 \mathrm{~J} \mathrm{~cm}^{-2}$ (see ESI $\dagger$ for details). After irradiation, samples were returned to the water bath for an hour, before being checked for crystals. Any samples that had not nucleated were cooled to room temperature and nucleated by mechanical shock (hitting firmly on the bench top) before re-use. Control experiments at each temperature were carried out, where the vials were treated in the same way but not exposed to the laser pulse.

The behaviour of sodium bromide solutions at room temperature $\left(21^{\circ} \mathrm{C}\right)$ was investigated by cooling sample solutions slowly overnight. Each vial was exposed to a single pulse of laser light (1064 nm) with an incident energy density of $0.6 \mathrm{~J} \mathrm{~cm}^{-2}$ (see ESI $\dagger$ for details). In this case, near-infrared laser light was used to compare against visible light. We found that the wavelength of light used (532 or $1064 \mathrm{~nm}$ ) made no discernible difference to the observations. A digital camera with a macro-zoom lens was used to image the crystal growth at the bottom of the vial. Only samples that nucleated within one hour were counted.

Nucleation of samples by mechanical shock, sonocrystallization, and laser trapping (for $\mathrm{NaBr}$ in $\mathrm{D}_{2} \mathrm{O}$ ) was investigated at $21^{\circ} \mathrm{C}$. For investigation of MSIN, sample vials were (by hand) struck firmly at the base against a flat metal surface. For investigation of sonocrystallization, samples were immersed for approximately one second in an ultrasonic bath (Elmasonic S-30-H, $37 \mathrm{kHz}$, nominal power $80 \mathrm{~W}$ ) then left at room temperature, and checked periodically for crystals. The procedure was repeated each day for any samples which had not nucleated (for a maximum of 5 days). Control experiments were also carried out, in which samples were treated in the same way but the ultrasonic bath was not turned on.

For nucleation by laser trapping, a CW laser was used (1064 nm, Laser Quantum Ventus). $\mathrm{D}_{2} \mathrm{O}$ was used as the solvent to minimise heating over time by the laser at this wavelength. ${ }^{51,52}$ The phase diagram for $\mathrm{NaBr}$ in $\mathrm{D}_{2} \mathrm{O}$ is very similar to that in $\mathrm{H}_{2} \mathrm{O}$, with a slightly lower transition temperature of $47^{\circ} \mathrm{C} .{ }^{53}$ A metastable solution was prepared by dissolving the salt at $40{ }^{\circ} \mathrm{C}$ and adding $\mathrm{D}_{2} \mathrm{O}$ dropwise until the solution was stable on cooling to room temperature (21 ${ }^{\circ} \mathrm{C}$ ). The resulting concentration was $9.51 \mathrm{~mol} \mathrm{~kg}^{-1}$, which corresponds to a supersaturation of $S=1.08(\mathrm{DH})=0.88$ $(\mathrm{AH})$, i.e., the solution is undersaturated with respect to AH. ${ }^{53}$ Droplets of solution $(<0.5 \mu \mathrm{L})$ were arranged on top of a glass coverslip that was bonded within a container to inhibit evaporation. The laser was focused at the solution-air interface from underneath the droplet using a long-working distance objective (Mitutoyo 50×, NA = 0.42). The diameter of the beam at the focal spot was approximately $1.5 \mu \mathrm{m}$. The average power of the beam was controlled to be in the range 1.0-1.2 W, as measured after the objective with no sample in place. Crystal formation was recorded through the same objective, using a digital camera fitted with an optical filter to block the laser wavelength.

\section{Results}

\subsection{NPLIN and spontaneous nucleation}

Two morphologies of sodium bromide crystals were observed: (1) clear, cubic crystals that grow slowly to a maximum length of a few millimetres (Fig. 2a); (2) plate-like crystals that grow either very rapidly, filling the vial within a few seconds as a solid translucent mass (Fig. 2b), or growing more slowly into larger individual sheets, leaving some remaining solution (Fig. 2c). The plate-like crystals were stable at room temperature and were the type formed by spontaneous nucleation or by seeding with $\mathrm{AH}$ sodium bromide crystals (see ESI $\dagger$ for details). The crystal structures of the cubic and plate-like morphologies were determined by single-crystal $\mathrm{X}$-ray diffraction and assigned to anhydrous and dihydrate sodium bromide, respectively (see ESI $\uparrow$ for details). Solutions that had started to grow cubic crystals at room temperature could also nucleate plate-like crystals, either spontaneously, by seeding, or by being knocked: this result is consistent with the phase diagram shown in Fig. 1. The phase diagram normally represents the attainment of an equilibrium form. If $\mathrm{AH}$ and $\mathrm{DH}$ are both present in the same vessel below 51 ${ }^{\circ} \mathrm{C}$, one would expect to see $\mathrm{AH}$ transform to $\mathrm{DH}$ over time as equilibrium is achieved. How fast this happens (kinetics) depends on solution parameters such as temperature and the size of crystals.

Table 1 summarizes the number of vials nucleated and the type of crystals formed at different temperatures. At $50{ }^{\circ} \mathrm{C}$ and above, all crystals formed were $\mathrm{AH}$, which is the expected solid form above $51{ }^{\circ} \mathrm{C}$ (Fig. 1). Between one and $20 \mathrm{AH}$ crystals formed in each vial. The lack of nucleation in the corresponding control experiments means we have confidence that these crystals were nucleated by the laser. At $45{ }^{\circ} \mathrm{C}$, some $\mathrm{DH}$ crystals were formed in the laser experiments: one or two plate-like sheets appeared in each vial. Since DH crystals were also formed in the control experiments at this temperature, it is not certain if these crystals were laser-induced or not.

In contrast to the results at $45-60{ }^{\circ} \mathrm{C}$, when samples were cooled to room temperature $\left(21^{\circ} \mathrm{C}\right)$, it was found that many samples nucleated spontaneously due to the high supersaturations being accessed $(S=1.12-1.29)$. Spontaneous nucleation resulted in the formation of $\mathrm{DH}$ crystals in all cases except one. Increasing the temperature at which the samples were dissolved significantly reduced the occurrence of spontaneous nucleation. When samples were dissolved at $75{ }^{\circ} \mathrm{C}$, spontaneous nucleation occurred in $34 / 43$ vials on cooling, but at $90{ }^{\circ} \mathrm{C}$ the frequency of spontaneous nucleation reduced to $7 / 52$ vials. It is possible that the higher temperature ensures dissolution of all solids and aids in degassing the solution, making the samples less liable to nucleation when being handled.

Table 2 shows the number of samples nucleated at $21{ }^{\circ} \mathrm{C}$ after exposure to the laser. Remarkably, only 2/23 samples formed $\mathrm{DH}$ after nucleation. In particular, the majority (21/ 22) of $11.5 \mathrm{~mol} \mathrm{~kg}^{-1}$ samples formed $\mathrm{AH}$ sodium bromide. 


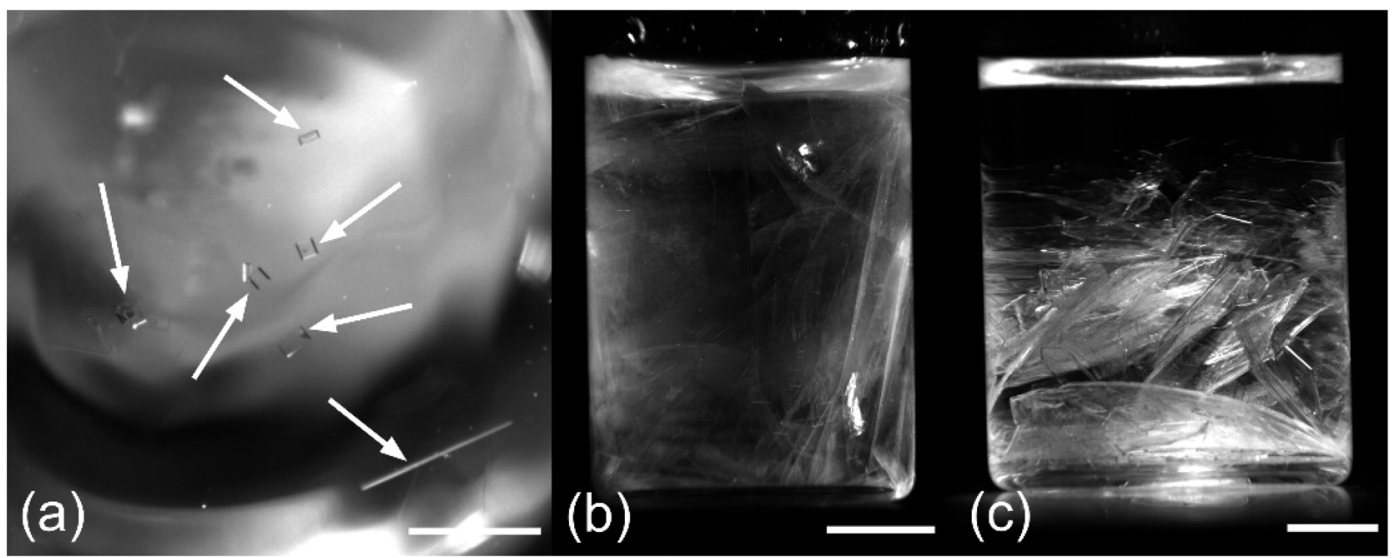

Fig. 2 Images of the different crystal morphologies formed from aqueous supersaturated solutions of sodium bromide: (a) small colourless cubic crystals (AH) (scale bar $=2 \mathrm{~mm}$ ), (b) a translucent mass consisting of flat plates of crystals $(\mathrm{DH})$ that fill the original solution (scale bar $=5 \mathrm{~mm})$, (c) transparent flat plates $(\mathrm{DH})$ leaving a larger fraction of solution at the top (scale bar $=5 \mathrm{~mm}$ ). Solution conditions: $C=11.5 \mathrm{~mol} \mathrm{~kg}^{-1}, T=21{ }^{\circ} \mathrm{C}, S=$ $1.29(\mathrm{DH})$ or $1.02(\mathrm{AH})$.

The AH crystals grew very slowly, and were visible by eye only after 20-30 minutes. However, closer examination of the recorded images showed crystallites falling to the bottom of the vial 10-100 s after the laser pulse. Fig. 3 shows the growth of a typical group of laser-induced $\mathrm{AH}$ crystals following exposure to a laser pulse.

\subsection{Nucleation by mechanical shock and sonocrystallization}

Samples that were nucleated deliberately by mechanical shock $\left(T=21{ }^{\circ} \mathrm{C}\right)$ always formed $\mathrm{DH}$ crystals. One hit was usually sufficient, although in some cases two or three hits were required. Two different growth behaviours were observed. (1) In some samples, nucleation occurred in localised regions of the solution, often near the solution-air interface (Fig. 4), possibly where liquid had splashed up the walls of the vial. Plate-like crystals grew outwards from these regions until the entire solution was filled with a translucent mass. (2) In other samples, a larger number of nucleation centres were observed throughout the solution (Fig. 5). Smaller plate-like crystals formed and fell to the bottom of the vial: these crystals were smaller and grew more quickly than case (1).
Table 3 shows the number of samples that nucleated after immersion in the ultrasonic bath, compared to the control samples. Only DH crystals were observed, except for ultrasonication at concentrations above saturation for $\mathrm{AH}$ (11.5 mol kg-1) where approximately half of the samples nucleated produced AH crystals.

\subsection{Laser-trapping nucleation}

Only AH crystals were observed in the laser trapping of solutions of $\mathrm{NaBr}$ in $\mathrm{D}_{2} \mathrm{O}$. In each of several droplets, a single cubic crystal was observed growing at or near the focal point within $10 \mathrm{~s}$ to 4 minutes of exposure to the beam. The growth rate of the crystals could be controlled by adjusting the laser power: at the maximum power $(1.2 \mathrm{~W})$ steady growth was maintained; while at lower power $(1.0 \mathrm{~W})$ slower growth occurred, and the crystal was less stable in the trap. The crystal could be translated along the interface while trapped as it was pinned by the laser to the interface, but moving the focal volume into the solution resulted in loss of trapping. Trapped crystals were observed to grow out from the focus of the laser, as shown in Fig. 5 (see Video S5 in ESI $\dagger$ ). When nucleation was first observed, the crystals produced $(<1 \mu \mathrm{m})$

Table 1 NPLIN of NaBr crystals in the range of temperatures $45-60{ }^{\circ} \mathrm{C}$. The nominal supersaturation of the solution (11.5 mol kg-1) with respect to each crystal form is shown ( $\mathrm{DH}=$ dihydrate; $\mathrm{AH}=$ anhydrous). The table shows the number of vials that nucleated after exposure to a single laser pulse (532 $\mathrm{nm}$ ), in comparison to a control experiment with no laser. Samples that nucleated during the initial hour of cooling prior to exposure were excluded, hence the variation in the total number of samples tested

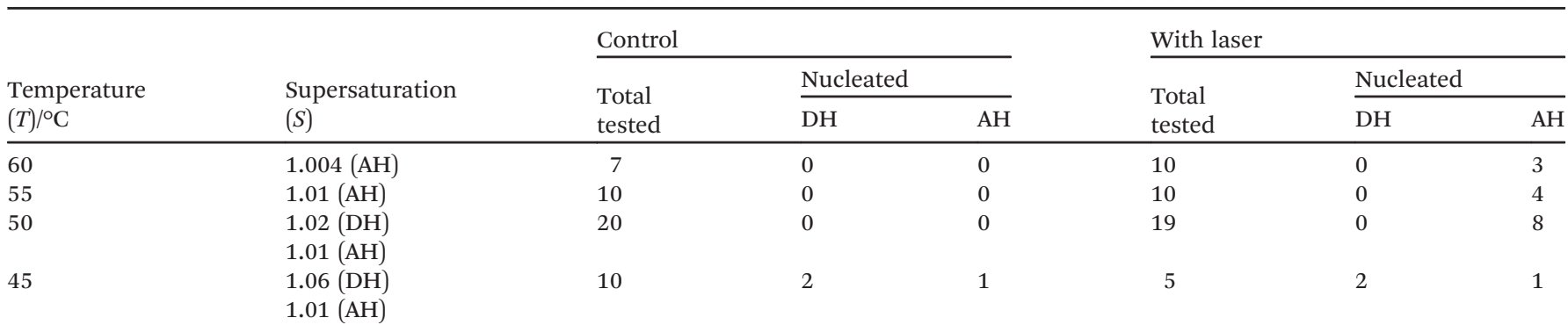


Table 2 NPLIN of $\mathrm{NaBr}$ crystals at $21^{\circ} \mathrm{C}$. The supersaturation with respect to each crystal form is shown ( $\mathrm{DH}=$ dihydrate; $\mathrm{AH}=$ anhydrous). The table shows the number of vials of solution that nucleated (out of the total tested) after exposure to a single laser pulse (1064 nm). Samples that nucleated spontaneously during the slow cooling overnight, prior to testing, were not counted

\begin{tabular}{lllll}
\hline $\begin{array}{l}\text { Concentration } \\
(C) / \mathrm{mol} \mathrm{kg}^{-1}\end{array}$ & $\begin{array}{l}\text { Supersaturation } \\
(S)\end{array}$ & $\begin{array}{l}\text { Total } \\
\text { tested }\end{array}$ & $\begin{array}{l}\text { Nucleated } \\
\text { with laser }\end{array}$ \\
\hline 11.5 & $1.29(\mathrm{DH})$ & 30 & 1 & $\mathrm{AH}$ \\
10.9 & $\begin{array}{l}1.02(\mathrm{AH}) \\
1.22(\mathrm{DH})\end{array}$ & 6 & 1 & 0 \\
10.0 & $\begin{array}{l}0.97(\mathrm{AH}) \\
1.12(\mathrm{DH})\end{array}$ & 4 & 0 & 0 \\
& $0.89(\mathrm{AH})$ & & &
\end{tabular}

tended to reorientate or spin in the trap due to asymmetry in the shape of the crystal. After some growth $(>3 \mu \mathrm{m})$ a morestable trapping configuration was obtained, with the crystal being pinned at an edge or corner, and sometimes jumping from trapping at one corner to another.

\section{Discussion}

A summary of the observed preferences for hydrate formation using the different methods is given in Table 4 . We can group the methods into three categories: (1) strong preference for DH crystals (spontaneous and mechanical shock); (2) both $\mathrm{DH}$ and $\mathrm{AH}$ can be formed (sonocrystallization); (3) strong preference for $\mathrm{AH}$ crystals (NPLIN, laser trapping). In the remainder of the discussion, we use the results to extract features of the mechanisms involved.

\subsection{Laser-trapping nucleation}

The preference for nucleation of $\mathrm{AH}$ via laser-trapping is remarkable because the starting solution at $T=21{ }^{\circ} \mathrm{C}$ was supersaturated with respect to $\mathrm{DH}(S=1.08)$ but undersaturated with respect to $\mathrm{AH}(S=0.88)$. The ability to nucleate crystals in undersaturated solutions was first reported by Sugiyama and co-workers for glycine in $\mathrm{D}_{2} \mathrm{O} .^{54}$ The CW laser at $1064 \mathrm{~nm}$ is expected to cause localised heating due to absorption by the water (vibrational overtones), but the use of $\mathrm{D}_{2} \mathrm{O}$ rather than $\mathrm{H}_{2} \mathrm{O}$ limits this effect to approximately $2 \mathrm{~K} \mathrm{~W}^{-1}$ of laser power. ${ }^{51,52}$ Therefore, the observed preference cannot be explained simply by elevation of solution above the transition temperature of $47^{\circ} \mathrm{C}$, where $\mathrm{AH}$ becomes the preferred solid form in $\mathrm{D}_{2} \mathrm{O}$ (Fig. 1).

Yuyama et al. have conducted detailed studies on lasertrapping nucleation of the hydrate system L-phenylalanine ( $\mathrm{L}$ Phe) in water. ${ }^{15,46,51,55-57}$ Monohydrate ( $\mathrm{MH}$ ) $\mathrm{L}$-Phe is the stable crystal form at room-temperature, and anhydrous $\mathrm{L}$-Phe $(\mathrm{AH})$ is the stable form above $36{ }^{\circ} \mathrm{C}$. For L-Phe in $\mathrm{H}_{2} \mathrm{O}$ a

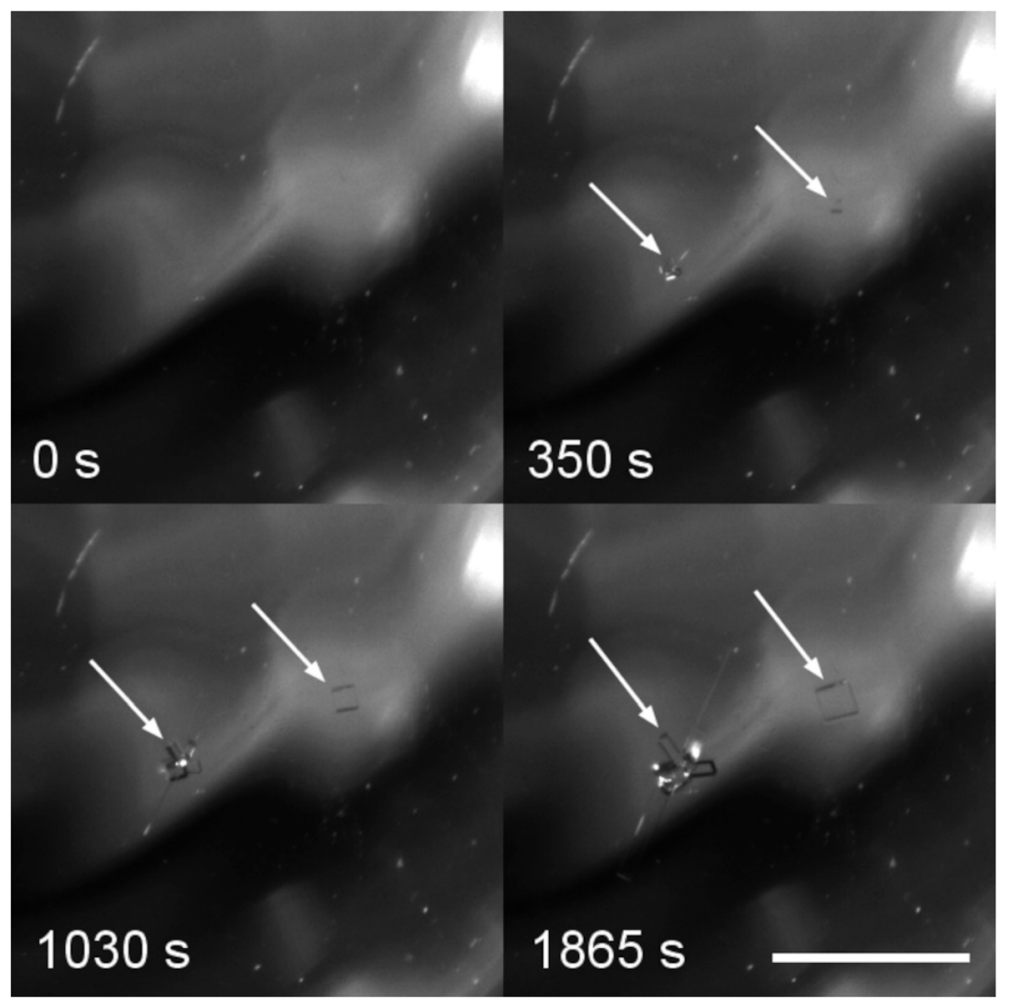

Fig. 3 Images of crystal growth of $\mathrm{NaBr}(\mathrm{AH})$ from an aqueous supersaturated solution following NPLIN. Solution conditions: $C=11.5$ mol kg ${ }^{-1}, T$ $=21{ }^{\circ} \mathrm{C}, \mathrm{S}=1.29(\mathrm{DH})$ or $1.02(\mathrm{AH})$. The crystals were imaged through the bottom of the vial and are shown between 0 and 31 minutes after the laser pulse $(1064 \mathrm{~nm})$. Crystals were first visible approximately $25 \mathrm{~s}$ after the laser pulse. Scale bar represents $2 \mathrm{~mm}$. 


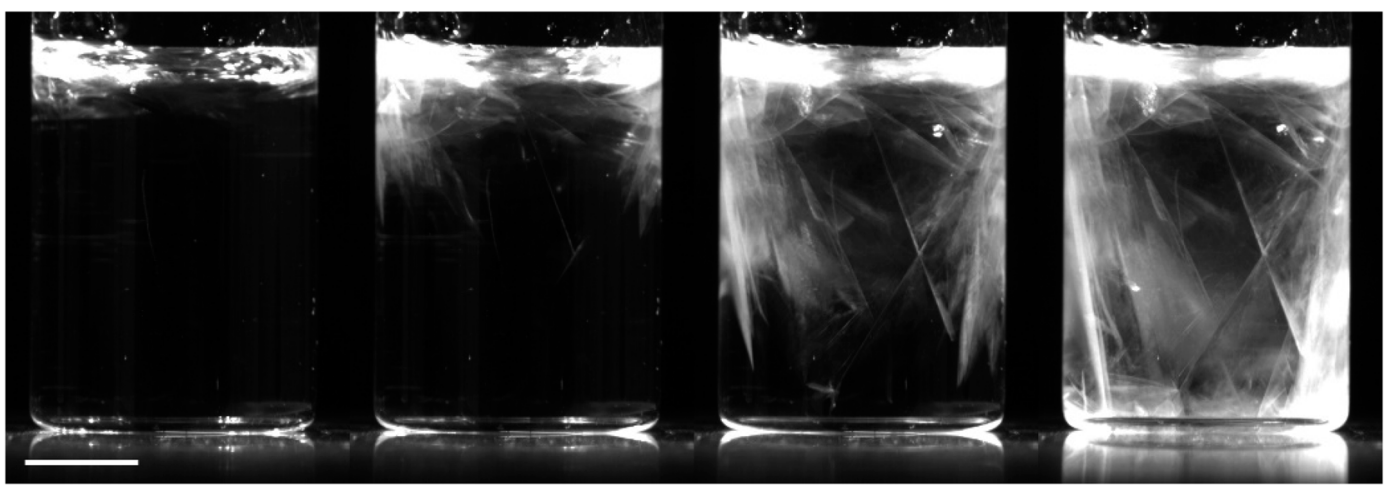

Fig. 4 Nucleation by mechanical shock case (1) where nucleation occurred near the solution-air interface. Images of crystal growth of $\mathrm{NaBr}$ (DH) from an aqueous supersaturated solution following nucleation by mechanical shock, from left to right: $3.4,9,14$, and $19 \mathrm{~s}$ after nucleation. Solution conditions: $C=10.9 \mathrm{~mol} \mathrm{~kg}^{-1}, T=21{ }^{\circ} \mathrm{C}, S=1.22(\mathrm{DH})$ or $0.97(\mathrm{AH})$. Scale bar represents $5 \mathrm{~mm}$.

plate-like AH crystal was formed at the focal point, which grew out from its centre in all directions. ${ }^{46}$ For $\mathrm{L}$-Phe in $\mathrm{D}_{2} \mathrm{O}$, needle-shaped $\mathrm{MH}$ crystals nucleated, but only far away $(>500 \mu \mathrm{m})$ from the laser focal volume. ${ }^{51}$ It was considered that in $\mathrm{D}_{2} \mathrm{O}$, the interaction between laser and solute at the focal point is much stronger than in $\mathrm{H}_{2} \mathrm{O}$, to the extent that nucleation is hindered there. Nucleation may then occur outside the focal area, where the local structure of the solution favours $\mathrm{MH}$. In the present work, we see growth of a cubic crystal outwards from a trapped corner (Fig. 6), which is likely due to the cubic morphology of $\mathrm{AH} \mathrm{NaBr}$ versus the plate-like morphology of AH L-Phe.

Cheng et al. studied laser-trapping nucleation of $\mathrm{KCl}$ in $\mathrm{D}_{2} \mathrm{O} .^{52}$ At low laser powers $(0.4 \mathrm{~W})$ the crystal morphology was needle-shaped, but at higher laser powers $(1.2 \mathrm{~W})$ a cubic morphology was obtained, similar to the present work. $\mathrm{KCl}$ is not known to form hydrates under ambient conditions, and the needle morphology was attributed to growth at high supersaturation. The high concentration was possibly built up over tens of minutes of exposure to the laser prior to nucleation.

Based on previous mechanisms described by Sugiyama and co-workers, we consider that for aqueous $\mathrm{NaBr}$ solutions, the laser acts to build-up concentration of solute around the focal volume. ${ }^{54}$ By the time nucleation happens, the local concentration is above the AH solubility line. This can be thought of as an almost vertical transition on the phase diagram, from the bulk concentration (red triangle, Fig. 1) to above the AH solubility curve (dashed curve, Fig. 1). In the case of $\mathrm{NaBr}$ in $\mathrm{D}_{2} \mathrm{O}$, this transition would require an increase from $9.51 \mathrm{~mol} \mathrm{~kg}^{-1}$ to above $10.8 \mathrm{~mol} \mathrm{~kg}^{-1}$, which is a $14 \%$ increase in local concentration. The observation that AH nucleates instead of DH is consistent with Ostwald's rule of stages, which states that the more thermodynamically unstable form will tend to nucleate first. Because the trapping method only creates one localised crystal, there are no DH crystals to promote transition to the more stable form.

We note that $\mathrm{D}_{2} \mathrm{O}$ was used as solvent in the lasertrapping experiments only to prevent heating during longterm exposure to the $1064 \mathrm{~nm} \mathrm{CW}$ trapping beam. A similar experiment could be conducted with $\mathrm{NaBr}$ in $\mathrm{H}_{2} \mathrm{O}$ using a $\mathrm{CW}$ beam at a different wavelength (e.g., $532 \mathrm{~nm}$ ) where heating of the solvent would be minimal. We expect this would produce results identical to the present work, i.e., nucleation of AH crystals.

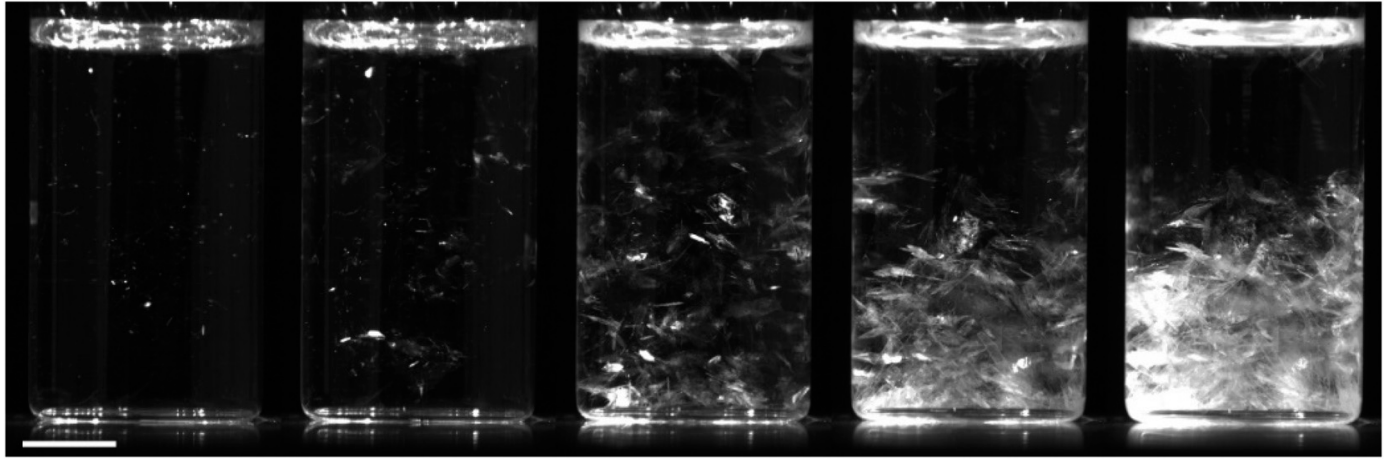

Fig. 5 Nucleation by mechanical shock case (2) where nuclei are initially formed in the bulk of the solution. Images of crystal growth of $\mathrm{NaBr}$ (DH) from an aqueous supersaturated solution following nucleation by mechanical shock, from left to right: $0.5,2.8,10,17$, and $34 \mathrm{~s}$ after nucleation. Solution conditions: $C=10.0 \mathrm{~mol} \mathrm{~kg}{ }^{-1}, T=21^{\circ} \mathrm{C}, S=1.12(\mathrm{DH})$ or 0.89 (AH). Scale bar represents $5 \mathrm{~mm}$. 
Table 3 Nucleation by sonocrystallization. The nominal supersaturation with respect to each crystal form is shown (DH = dihydrate; $\mathrm{AH}=$ anhydrous). The table shows the number of aqueous sodium bromide samples that nucleated after immersion in an ultrasonic bath for approximately one second, with a maximum of five consecutive attempts, at $21^{\circ} \mathrm{C}$

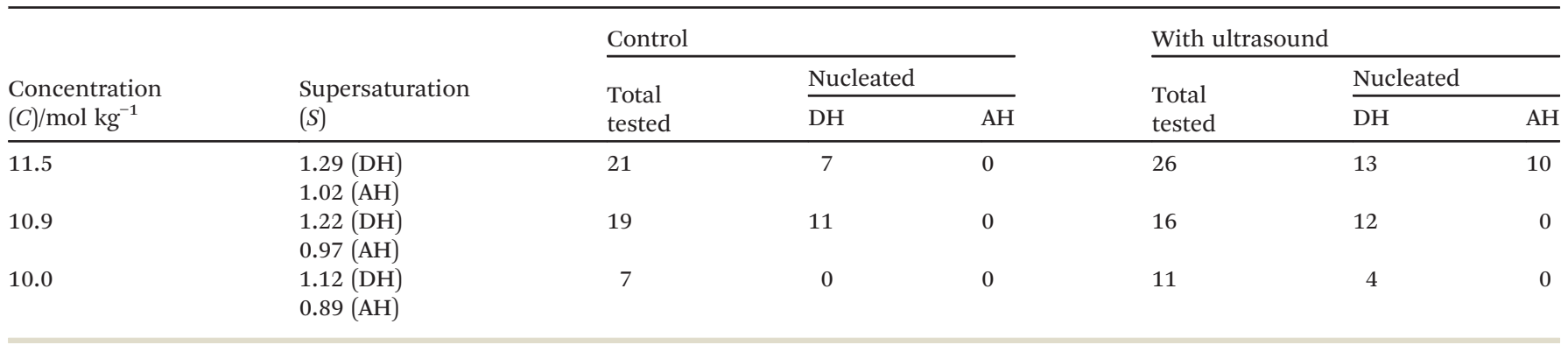

\subsection{Pulsed-laser NPLIN}

The pulsed-laser NPLIN results show a strong preference for $\mathrm{AH}(90 \%)$. This preference can be rationalised in terms of the particle-heating mechanism for NPLIN. ${ }^{20,37,40}$ The mechanism we describe here draws from the experiments of Soare et al. and corresponding simulations of Hidman et $a l .{ }^{58,59}$ In their work, crystal nucleation was induced following absorption of a focused laser pulse $\left(\sim 5 \mathrm{~kJ} \mathrm{~cm}^{-2}\right)$ in a supersaturated solution, leading to thermocavitation. By contrast, in the present work the energy density $\sim 1 \mathrm{~J} \mathrm{~cm}^{-2}$ is substantially lower, and the absorbing medium is not the solution itself but nanoparticles in solution.

The mechanism is illustrated in Fig. 7. A rapid increase in temperature occurs due to absorption of the laser pulse by a solid nanoparticle (NP). Based on previous findings, the NP is likely to be a trace impurity in the solution, such as iron oxide or carbon. ${ }^{20,39}$ The transient high temperature produces a layer of superheated layer (SHL) of liquid around the particle, leading to rapid vaporization and formation of an expanding cavity, i.e., thermocavitation. ${ }^{60}$ Vaporization continues from an interfacial layer (IL) at the expanding gasliquid interface, giving rise to increased local supersaturation (Fig. 7c). The IL is a region of dehydration, which leads to the strong preference for $\mathrm{AH}$ while hindering formation of $\mathrm{DH}$.

With reference to the phase diagram (Fig. 1) at $21^{\circ} \mathrm{C}$, at the highest experimental concentration (just above the $\mathrm{AH}$ solubility curve) 22/30 samples nucleated, of which 21 were AH. Below this line, only $1 / 10$ samples nucleated, producing $\mathrm{DH}$. This means that NPLIN operates in the region near or above the AH line. We should be cautious and note, however, that we only record events that result in successful growth of a crystal. It is possible that nuclei are formed but redissolve before they have grown sufficiently large to survive for us to observe the outcome.

\subsection{Sonocrystallization and mechanical shock}

The use of sonocrystallization for nucleation and control of particle size is well established, and acoustic cavitation is considered to be the primary cause. ${ }^{61}$ The cavitation that takes place is induced by shear from pressure waves travelling through the liquid. We believe this causes colder and less-dehydrating nucleation events than NPLIN: at least under ultrasonic bath frequency and power conditions used in the present work. The observed branching between $\mathrm{DH}$ and $\mathrm{AH}$ neatly represents the position of the initial solution on the phase diagram: at experimental points below the $\mathrm{AH}$ solubility line only $\mathrm{DH}$ was observed; above this line we observed nucleation of almost equal numbers of $\mathrm{AH}$ and $\mathrm{DH}$ samples. We note that the exposure time to ultrasound in the present work was fixed at $1 \mathrm{~s}$, in order to focus on primary nucleation. Longer exposure times would modify the ratio of $\mathrm{AH}$ to $\mathrm{DH}$, since secondary nucleation will also become important.

The method we used for MSIN involves striking the base of the vial on a hard surface. A similar method is used in the common prank of beer tapping, where sharp knocking of a carbonated beer bottle releases a foam of bubbles. ${ }^{62}$ The rapid acceleration of the vessel causes liquid shear and cavitation. We previously used MSIN to study nucleation of $\alpha$ and $\gamma$ polymorphs of glycine. ${ }^{30}$ We found that the probability of nucleating $\gamma$-glycine crystals increased more sharply as a function of supersaturation using NPLIN compared to MSIN. We interpreted the results by suggesting that NPLIN accessed higher local supersaturations. ${ }^{30}$ The results of the present work now suggest that the interface of the expanding cavity in NPLIN is also hotter, more dehydrating, which leads to the preference for $\mathrm{AH}$ crystals. Relative to NPLIN and sonocrystallization, we consider shock to cause colder cavitation events, and therefore we observe a stronger preference $(100 \%)$ for $\mathrm{DH}$.

Finally, we comment on the observations of spontaneous nucleation. Spontaneous, homogeneous

Table 4 Summary of preferences for $\mathrm{NaBr}$ crystal phases using different nucleation methods ( $\mathrm{DH}=$ dihydrate; $\mathrm{AH}=$ anhydrous). For laser trapping, $\mathrm{D}_{2} \mathrm{O}$ was used as solvent; for all the other methods $\mathrm{H}_{2} \mathrm{O}$ was used

\begin{tabular}{ll}
\hline Nucleation method & NaBr preferred solid form \\
\hline Spontaneous & DH $(95 \%)$ \\
Mechanical shock & DH $(100 \%)$ \\
Sonocrystallization & DH $(74 \%)$ \\
NPLIN (pulsed laser) & AH $(90 \%)$ \\
Laser trapping (CW laser) & AH $(100 \%)$
\end{tabular}



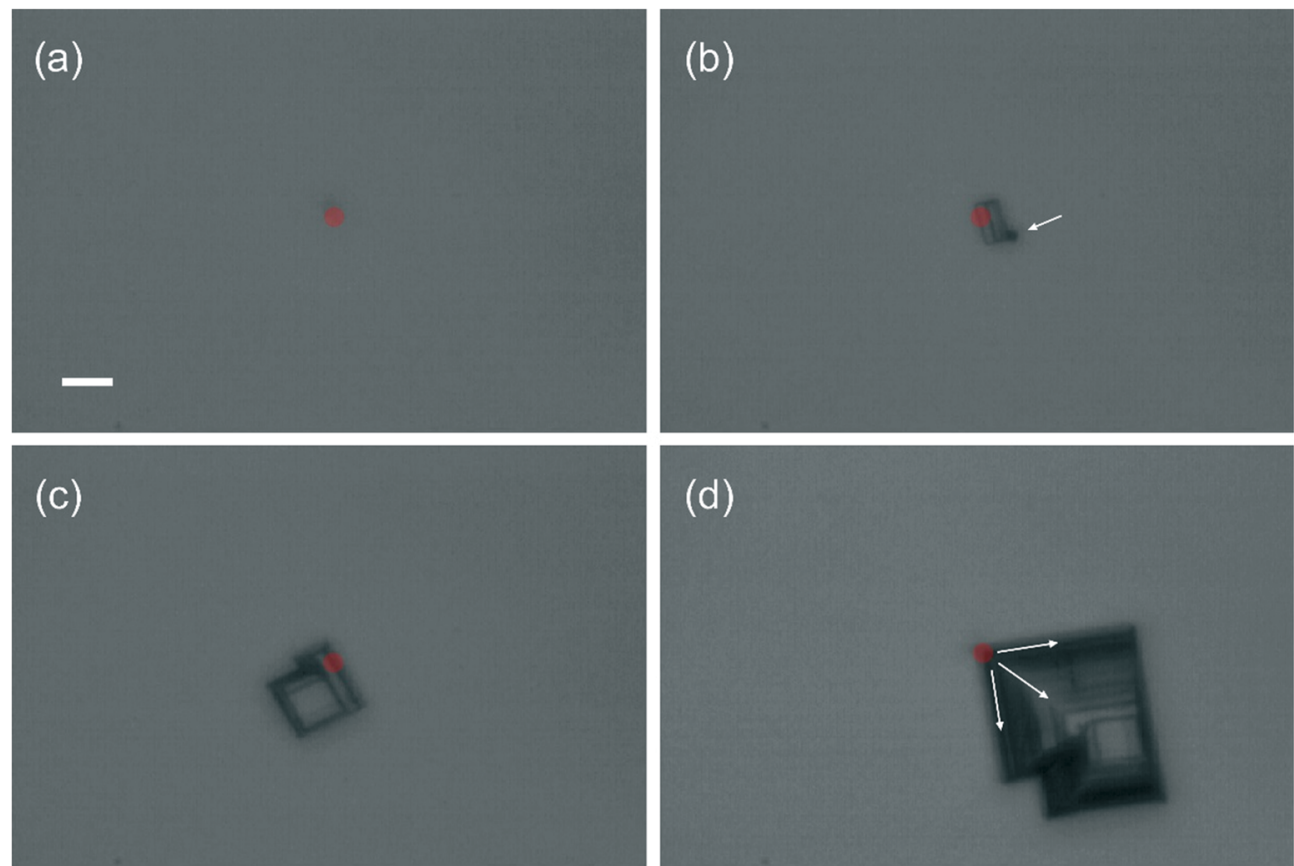

Fig. 6 Laser-trapping nucleation and crystal growth of $\mathrm{NaBr}(\mathrm{AH})$ from an aqueous supersaturated solution in $\mathrm{D}_{2} \mathrm{O}$. Solution conditions: $\mathrm{C}=9.51$ mol kg${ }^{-1}, T=21{ }^{\circ} \mathrm{C}, \mathrm{S}=1.08(\mathrm{DH})$ or $0.88(\mathrm{AH})$. Laser power was $1.0 \mathrm{~W}$ at $1064 \mathrm{~nm}$. The scale bar represents $10 \mu \mathrm{m}$. The transparent red dot represents the location of the laser focus in the image plane (focal size not to scale). Images taken at times (a) $11 \mathrm{~s}$, (b) $64 \mathrm{~s}$, (c) $78 \mathrm{~s}$, and (d) $110 \mathrm{~s}$ after laser was focussed at solution-air interface of droplet. The arrow in (b) shows a small crystallite attached to the main crystal. The arrow in (d) indicates the direction of growth of the crystal, outward from the laser focus, which can be followed by the crystalline steps visible on the crystal. See $\mathrm{ESI} \uparrow$ (Video S5) for a movie of the nucleation and trapping.

primary nucleation is highly unlikely under normal laboratory conditions. ${ }^{63}$ Therefore, heterogeneous mechanisms are more likely to be responsible, e.g., on dust or trace impurities, or cavities. Table 4 shows a strong preference $(>95 \%)$ for $\mathrm{DH}$ for both spontaneous nucleation and mechanical shock. In the present work, movement of the samples was unavoidable, and it's possible that what we call spontaneous nucleation was caused by mechanical shock. It is also possible that spontaneous nucleation is mediated by cavitation events caused by background particle radiation, such as cosmic rays. ${ }^{60}$

\section{Conclusions}

In summary, we have conducted a study of hydrate formation in aqueous sodium bromide. We found that both spontaneous nucleation and nucleation by mechanical shock strongly favoured sodium bromide DH crystals. Using sonocrystallization, the branching between $\mathrm{AH}$ and $\mathrm{DH}$ crystal forms could be rationalised in terms of the supersaturation with respect to each form, with reference to the solution phase diagram. Laser-trapping nucleation (in $\mathrm{D}_{2} \mathrm{O}$ ) showed a complete preference for $\mathrm{AH}$, and it was possible to nucleate solutions that were undersaturated with
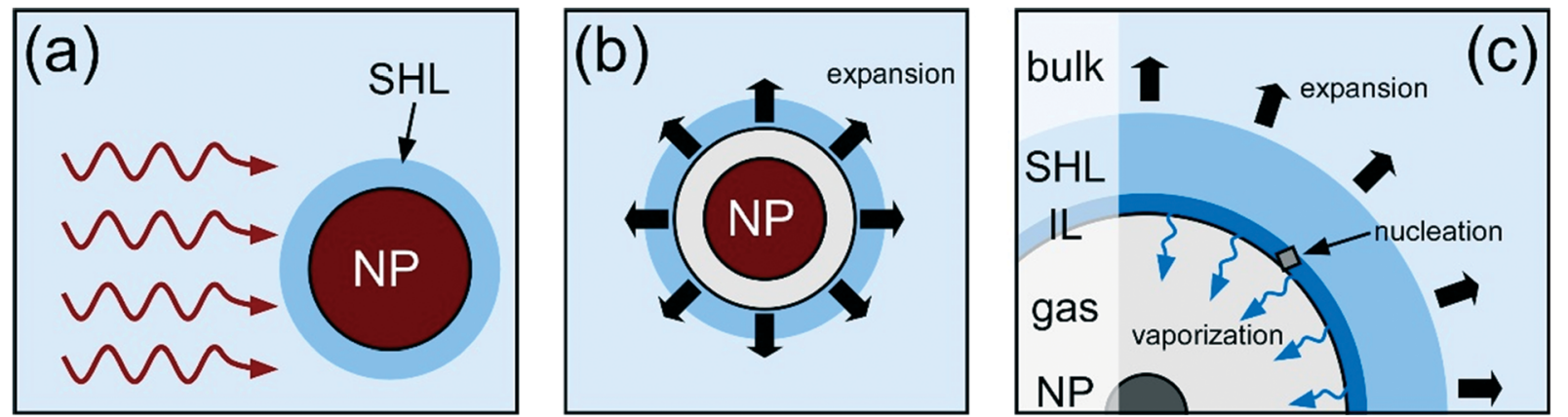

Fig. 7 Schematic diagram of the proposed mechanism for pulsed-laser NPLIN (see section 4.2). (a) A trace nanoparticle (NP) absorbs laser light and the heat transferred to the solution results in a superheated layer (SHL) of liquid. (b) Vaporization in the SHL results in a rapidly expanding vapor cavity. (c) The hot solvent is vaporized from an interfacial layer (IL) at the expanding gas-liquid interface. A crystal nucleus is formed in the $\mathrm{IL}$, which favours $\mathrm{AH}$ due to the localised concentration and temperature. 
respect to the $\mathrm{AH}$ solubility curve. NPLIN with single nanosecond laser pulses was almost entirely ineffective below the AH solubility curve, but gave a very strong preference for $\mathrm{AH}$ when supersaturated with respect to this phase. The results suggest that nucleation of crystal hydrates might in general be controlled by choice of method and knowledge of the phase diagram. From the results we have inferred new and useful details of the nucleation mechanisms involved. In particular, the results suggest that NPLIN causes cavitation events where the cavity interface is hotter, and therefore more dehydrating, than in sonocrystallization or nucleation by mechanical shock.

\section{Data availability}

Data employed in this study are available via the Edinburgh DataShare repository (DOI: 10.7488/ds/3166x).

\section{Conflicts of interest}

There are no conflicts to declare.

\section{Acknowledgements}

We are grateful to the Engineering and Physical Sciences Research Council for funding a Doctoral studentship for ERB (EP/N509644/1), and to the CMAC Future Manufacturing Research Hub (http://www.cmac.ac.uk) for supporting this work. We thank the Science and Technology Facilities Council (STFC) for access to the Central Laser Facility (CLF) Lasers for Science Facility (LSF Access App. No. 1923011).

\section{References}

1 A. Llinàs and J. M. Goodman, Polymorph Control: Past, Present and Future, Drug Discovery Today, 2008, 13(5-6), 198-210, DOI: 10.1016/j.drudis.2007.11.006.

2 J. Bernstein, Polymorphism in Molecular Crystals, Oxford University Press, Oxford, 2007.

3 J. K. Guillory, Generation of Polymorphs, Hydrates, Solvates, and Amorphous Solids, in Polymorphism in Pharmaceutical Solids, ed. H. G. Brittain, Drugs and the Pharmaceutical Sciences, Marcel Dekker, Inc., New York, 1999, vol. 95, pp. 183-226.

4 M. Kitamura, Strategy for Control of Crystallization of Polymorphs, CrystEngComm, 2009, 11(6), 949, DOI: 10.1039/ b809332f.

5 I. Weissbuch, V. Yu. Torbeev, L. Leiserowitz and M. Lahav, Solvent Effect on Crystal Polymorphism: Why Addition of Methanol or Ethanol to Aqueous Solutions Induces the Precipitation of the Least Stable $\beta$ Form of Glycine, Angew. Chem., Int. Ed., 2005, 44(21), 3226-3229, DOI: 10.1002/ anie.200500164.

6 M. Kitamura, T. Hara and M. Takimoto-Kamimura, Solvent Effect on Polymorphism in Crystallization of BPT Propyl Ester, Cryst. Growth Des., 2006, 6(8), 1945-1950, DOI: 10.1021/cg050464e.
7 T. Zhang, B. Szilágyi, J. Gong and Z. K. Nagy, Thermodynamic Polymorph Selection in Enantiotropic Systems Using Supersaturation-Controlled Batch and Semibatch Cooling Crystallization, Cryst. Growth Des., 2019, 19(11), 6715-6726, DOI: 10.1021/acs. cod.9b01076.

8 W. Beckmann, Seeding the Desired Polymorph: Background, Possibilities, Limitations, and Case Studies, Org. Process Res. Dev., 2000, 4(5), 372-383, DOI: 10.1021/op0000778.

9 I. Weissbuch, R. Popovitz-Biro, M. Lahav and L. Leiserowitz, Rehovot. Understanding and Control of Nucleation, Growth, Habit, Dissolution and Structure of Two- and ThreeDimensional Crystals Using 'Tailor-Made' Auxiliaries, Acta Crystallogr., Sect. B: Struct. Sci., 1995, 51(2), 115-148, DOI: 10.1107/S0108768194012061.

10 J. E. Aber, S. Arnold, B. A. Garetz and A. S. Myerson, Strong Dc Electric Field Applied to Supersaturated Aqueous Glycine Solution Induces Nucleation of the $\gamma$ Polymorph, Phys. Rev. Lett., 2005, 94(14), 145503, DOI: 10.1103/ PhysRevLett.94.145503.

11 S. Gracin, M. Uusi-Penttilä and Å. C. Rasmuson, Influence of Ultrasound on the Nucleation of Polymorphs of $\mathrm{p}$ Aminobenzoic Acid, Cryst. Growth Des., 2005, 5(5), 1787-1794, DOI: 10.1021/cg050056a.

12 Y. Mori, M. Maruyama, Y. Takahashi, K. Ikeda, S. Fukukita, H. Y. Yoshikawa, S. Okada, H. Adachi, S. Sugiyama, K. Takano, S. Murakami, H. Matsumura, T. Inoue, M. Yoshimura and Y. Mori, Selective Crystallization of Metastable Phase of Acetaminophen by Ultrasonic Irradiation, Appl. Phys. Express, 2015, 8(6), 065501, DOI: 10.7567/APEX.8.065501.

13 B. A. Garetz, J. Matic and A. S. Myerson, Polarization Switching of Crystal Structure in the Nonphotochemical Light-Induced Nucleation of Supersaturated Aqueous Glycine Solutions, Phys. Rev. Lett., 2002, 89(17), 175501, DOI: 10.1103/PhysRevLett.89.175501.

14 K. Yuyama, T. Rungsimanon, T. Sugiyama and H. Masuhara, Selective Fabrication of $\alpha$ - and $\gamma$-Polymorphs of Glycine by Intense Polarized Continuous Wave Laser Beams, Cryst. Growth Des., 2012, 12(5), 2427-2434, DOI: 10.1021/ cg300065x.

15 C.-S. Wu, P.-Y. Hsieh, K. Yuyama, H. Masuhara and T. Sugiyama, Pseudopolymorph Control of $\mathrm{L}$-Phenylalanine Achieved by Laser Trapping, Cryst. Growth Des., 2018, 18(9), 5417-5425, DOI: 10.1021/acs.cgd.8b00796.

16 B. A. Garetz, J. E. Aber, N. L. Goddard, R. G. Young and A. S. Myerson, Nonphotochemical, Polarization-Dependent, LaserInduced Nucleation in Supersaturated Aqueous Urea Solutions, Phys. Rev. Lett., 1996, 77(16), 3475-3476, DOI: 10.1103/PhysRevLett.77.3475.

17 A. J. Alexander and P. J. Camp, Single Pulse, Single Crystal Laser-Induced Nucleation of Potassium Chloride, Cryst. Growth Des., 2009, 9(2), 958-963, DOI: 10.1021/ cg8007415.

18 M. R. Ward and A. J. Alexander, Nonphotochemical LaserInduced Nucleation of Potassium Halides: Effects of 
Wavelength and Temperature, Cryst. Growth Des., 2012, 12(9), 4554-4561, DOI: 10.1021/cg300750c.

19 K. Fang, S. Arnold and B. A. Garetz, Nonphotochemical Laser-Induced Nucleation in Levitated Supersaturated Aqueous Potassium Chloride Microdroplets, Cryst. Growth Des., 2014, 14(5), 2685-2688, DOI: 10.1021/cg5004319.

20 M. R. Ward, A. M. Mackenzie and A. J. Alexander, Role of Impurity Nanoparticles in Laser-Induced Nucleation of Ammonium Chloride, Cryst. Growth Des., 2016, 16(12), 6790-6796, DOI: 10.1021/acs.cgd.6b00882.

21 R. Kacker, S. Dhingra, D. Irimia, M. K. Ghatkesar, A. Stankiewicz, H. J. M. Kramer and H. B. Eral, Multiparameter Investigation of Laser-Induced Nucleation of Supersaturated Aqueous KCl Solutions, Cryst. Growth Des., 2018, 18(1), 312-317, DOI: 10.1021/acs.cgd.7b01277.

22 T. Hua, O. Gowayed, D. Grey-Stewart, B. A. Garetz and R. L. Hartman, Microfluidic Laser-Induced Nucleation of Supersaturated Aqueous $\mathrm{KCl}$ Solutions, Cryst. Growth Des., 2019, 19(6), 3491-3497, DOI: 10.1021/acs. cgd.9b00362.

23 I. S. Lee, J. M. B. Evans, D. Erdemir, A. Y. Lee, B. A. Garetz and A. S. Myerson, Nonphotochemical Laser Induced Nucleation of Hen Egg White Lysozyme Crystals, Cryst. Growth Des., 2008, 8(12), 4255-4261, DOI: 10.1021/ cg800696u.

24 N. Yennawar, S. Denev, V. Gopalan and H. Yennawar, LaserImproved Protein Crystallization Screening, Acta Crystallogr., Sect. F: Struct. Biol. Cryst. Commun., 2010, 66(Pt 8), 969-972, DOI: $10.1107 / \mathrm{S} 1744309110023857$.

25 J. Zaccaro, J. Matic, A. S. Myerson and B. A. Garetz, Nonphotochemical, Laser-Induced Nucleation of Supersaturated Aqueous Glycine Produces Unexpected $\gamma$-Polymorph, Cryst. Growth Des., 2001, 1(1), 5-8, DOI: 10.1021/cg0055171.

26 X. Sun, B. A. Garetz and A. S. Myerson, Polarization Switching of Crystal Structure in the Nonphotochemical Laser-Induced Nucleation of Supersaturated Aqueous L Histidine ${ }^{\dagger}$, Cryst. Growth Des., 2008, 8(5), 1720-1722, DOI: $10.1021 / \mathrm{cg} 800028 \mathrm{v}$.

27 B. Clair, A. Ikni, W. Li, P. Scouflaire, V. Quemener and A. Spasojević-de Biré, A New Experimental Setup for HighThroughput Controlled Non-Photochemical Laser-Induced Nucleation: Application to Glycine Crystallization, J. Appl. Crystallogr., 2014, 47(4), 1252-1260, DOI: 10.1107/ S160057671401098X.

28 A. Ikni, B. Clair, P. Scouflaire, S. Veesler, J.-M. Gillet, N. El Hassan, F. Dumas and A. Spasojević-de Biré, Experimental Demonstration of the Carbamazepine Crystallization from Non-Photochemical Laser-Induced Nucleation in Acetonitrile and Methanol, Cryst. Growth Des., 2014, 14(7), 3286-3299, DOI: $10.1021 / \mathrm{cg} 500163 \mathrm{c}$.

29 W. Li, A. Ikni, P. Scouflaire, X. Shi, N. El Hassan, P. Gémeiner, J.-M. Gillet and A. Spasojević-de Biré, NonPhotochemical Laser-Induced Nucleation of Sulfathiazole in a Water/Ethanol Mixture, Cryst. Growth Des., 2016, 16(5), 2514-2526, DOI: 10.1021/acs.cgd.5b01526.
30 Y. Liu, M. H. van den Berg and A. J. Alexander, Supersaturation Dependence of Glycine Polymorphism Using Laser-Induced Nucleation, Sonocrystallization and Nucleation by Mechanical Shock, Phys. Chem. Chem. Phys, 2017, 19(29), 19386-19392, DOI: 10.1039/C7CP03146G.

31 T. Tasnim, A. Goh, O. Gowayed, C. T. Hu, T.-Y. Chen, J. E. Aber and B. A. Garetz, Dendritic Growth of Glycine from Nonphotochemical Laser-Induced Nucleation of Supersaturated Aqueous Solutions in Agarose Gels, Cryst. Growth Des., 2018, 18(10), 5927-5933, DOI: 10.1021/acs. cgd.8b00688.

32 O. Gowayed, T. Tasnim, J. J. Fuentes-Rivera, J. E. Aber and B. A. Garetz, Non-Photochemical Pulsed-Laser-Induced Nucleation in a Continuous-Wave-Laser-Induced PhaseSeparated Solution Droplet of Aqueous Glycine Formed by Optical Gradient Forces, Cryst. Growth Des., 2019, 19(12), 7372-7379, DOI: 10.1021/acs.cgd.9b01255.

33 D. Irimia, J. J. Shirley, A. S. Garg, D. P. A. Nijland, A. E. D. M. van der Heijden, H. J. M. Kramer and H. B. Eral, Influence of Laser Parameters and Experimental Conditions on Nonphotochemical Laser-Induced Nucleation of Glycine Polymorphs, Cryst. Growth Des., 2021, 21(1), 631-641, DOI: 10.1021/acs.cgd.0c01415.

34 M. R. Ward, G. W. Copeland and A. J. Alexander, Chiral Hide-and-Seek: Retention of Enantiomorphism in LaserInduced Nucleation of Molten Sodium Chlorate, J. Chem. Phys., 2011, 135(11), 114508, DOI: 10.1063/1.3637946.

35 M. R. Ward, S. McHugh and A. J. Alexander, NonPhotochemical Laser-Induced Nucleation of Supercooled Glacial Acetic Acid, Phys. Chem. Chem. Phys., 2012, 14(1), 90-93, DOI: 10.1039/C1CP22774B.

36 B. C. Knott, J. L. LaRue, A. M. Wodtke, M. F. Doherty and B. Peters, Communication: Bubbles, Crystals, and LaserInduced Nucleation, J. Chem. Phys., 2011, 134(17), 171102, DOI: 10.1063/1.3582897.

37 M. R. Ward, W. J. Jamieson, C. A. Leckey and A. J. Alexander, Laser-Induced Nucleation of Carbon Dioxide Bubbles, J. Chem. Phys., 2015, 142(14), 144501, DOI: 10.1063/ 1.4917022 .

38 X. Sun, B. A. Garetz and A. S. Myerson, Supersaturation and Polarization Dependence of Polymorph Control in the Nonphotochemical Laser-Induced Nucleation (NPLIN) of Aqueous Glycine Solutions, Cryst. Growth Des., 2006, 6(3), 684-689, DOI: 10.1021/cg050460+.

39 N. Javid, T. Kendall, I. S. Burns and J. Sefcik, Filtration Suppresses Laser-Induced Nucleation of Glycine in Aqueous Solutions, Cryst. Growth Des., 2016, 16(8), 4196-4202, DOI: 10.1021/acs.cgd.6b00046.

40 A. J. Alexander and P. J. Camp, Non-Photochemical LaserInduced Nucleation, J. Chem. Phys., 2019, 150(4), 040901, DOI: $10.1063 / 1.5079328$.

41 K. Ikeda, M. Maruyama, Y. Takahashi, Y. Mori, H. Y. Yoshikawa, S. Okada, H. Adachi, S. Sugiyama, K. Takano, S. Murakami, H. Matsumura, T. Inoue, M. Yoshimura and Y. Mori, Selective Crystallization of the Metastable Phase of Indomethacin at the Interface of Liquid/Air Bubble Induced 
by Femtosecond Laser Irradiation, Appl. Phys. Express, 2015, 8(4), 045501, DOI: 10.7567/APEX.8.045501.

42 Y. Tsuri, M. Maruyama, R. Fujimoto, S. Okada, H. Adachi, H. Y. Yoshikawa, K. Takano, S. Murakami, H. Matsumura, T. Inoue, K. Tsukamoto, M. Imanishi, M. Yoshimura and Y. Mori, Crystallization of Aspirin Form II by Femtosecond Laser Irradiation, Appl. Phys. Express, 2019, 12(1), 015507, DOI: 10.7567/1882-0786/aaf419.

43 S. Wang, S. Wang, L. Jiang, M. Wang, Y. Wei, J. Sun, S. Zhan, X. Li and L. Qu, Polymorph-Controlled Crystallization of Acetaminophen through Femtosecond Laser Irradiation, Cryst. Growth Des., 2019, 19(6), 3265-3271, DOI: 10.1021/acs. cgd.9b00123.

44 T. Sugiyama, T. Adachi and H. Masuhara, Crystallization of Glycine by Photon Pressure of a Focused CW Laser Beam, Chem. Lett., 2007, 36(12), 1480-1481, DOI: 10.1246/ cl.2007.1480.

45 T. Rungsimanon, K. Yuyama, T. Sugiyama, H. Masuhara, N. Tohnai and M. Miyata, Control of Crystal Polymorph of Glycine by Photon Pressure of a Focused Continuous Wave Near-Infrared Laser Beam, J. Phys. Chem. Lett., 2010, 1(3), 599-603, DOI: 10.1021/jz900370x.

46 K. Yuyama, T. Sugiyama and H. Masuhara, Laser Trapping and Crystallization Dynamics of L-Phenylalanine at Solution Surface, J. Phys. Chem. Lett., 2013, 4(15), 2436-2440, DOI: 10.1021/jz401122v.

47 C.-S. Wu, H. Y. Yoshikawa and T. Sugiyama, Bidirectional Polymorphic Conversion by Focused Femtosecond Laser Irradiation, Jpn. J. Appl. Phys., 2020, 59(SI), SIIH02, DOI: 10.35848/1347-4065/ab7ae2.

48 W. F. Linke, Solubilities, Inorganic and Metal-Organic Compounds, American Chemical Society, Washington, 4th edn, 1958, vol. 2.

49 R. D. Eddy and A. W. C. Menzies, The Solubilities of Certain Inorganic Compounds in Ordinary Water and in Deuterium Water, J. Phys. Chem., 1940, 44(2), 207-235, DOI: 10.1021/ j150398a007.

50 W. F. Green, The "Melting-Point" of Hydrated Sodium Acetate: Solubility Curves, J. Phys. Chem., 1908, 12(9), 655-660, DOI: 10.1021/j150099a002.

51 K. Yuyama, C. S. Wu, T. Sugiyama and H. Masuhara, Laser Trapping-Induced Crystallization of L-Phenylalanine through Its High-Concentration Domain Formation, Photochem. Photobiol. Sci., 2014, 13(2), 254-260, DOI: 10.1039/c3pp50276g.

52 A. C. Cheng, H. Masuhara and T. Sugiyama, Evolving Crystal Morphology of Potassium Chloride Controlled by Optical Trapping, J. Phys. Chem. C, 2020, 124(12), 6913-6921, DOI: 10.1021/acs.jpcc.9b11651.
53 R. D. Eddy and A. W. C. Menzies, The Solubilities of Certain Inorganic Compounds in Ordinary Water and in Deuterium Water, J. Phys. Chem., 1940, 44(2), 207-235, DOI: 10.1021/ j150398a007.

54 T. Rungsimanon, K. Yuyama, T. Sugiyama and H. Masuhara, Crystallization in Unsaturated Glycine/D2O Solution Achieved by Irradiating a Focused Continuous Wave Near Infrared Laser, Cryst. Growth Des., 2010, 10(11), 4686-4688, DOI: $10.1021 / \operatorname{cg} 100830 x$.

55 K. I. Yuyama, J. George, K. G. Thomas, T. Sugiyama and H. Masuhara, Two-Dimensional Growth Rate Control of L-Phenylalanine Crystal by Laser Trapping in Unsaturated Aqueous Solution, Cryst. Growth Des., 2016, 16(2), 953-960, DOI: 10.1021/acs.cgd.5b01505.

56 K. Yuyama, D. S. Chiu, Y. E. Liu, T. Sugiyama and H. Masuhara, Crystal Growth and Dissolution Dynamics of L-Phenylalanine Controlled by Solution Surface Laser Trapping, Cryst. Growth Des., 2018, 18(11), 7079-7087, DOI: 10.1021/acs.cgd.8b01233.

57 J. J. K. Chen, K. Yuyama, T. Sugiyama and H. Masuhara, In Situ Reflection Imaging and Microspectroscopic Study on Three-Dimensional Crystal Growth of L-Phenylalanine under Laser Trapping, Appl. Phys. Express, 2019, 12(11), 5, DOI: 10.7567/1882-0786/ab4a9e.

58 A. Soare, R. Dijkink, M. R. Pascual, C. Sun, P. W. Cains, D. Lohse, A. I. Stankiewicz and H. J. M. Kramer, Crystal Nucleation by Laser-Induced Cavitation, Cryst. Growth Des., 2011, 11(6), 2311-2316, DOI: 10.1021/cg2000014.

59 N. Hidman, G. Sardina, D. Maggiolo, H. Ström and S. Sasic, Numerical Frameworks for Laser-Induced Cavitation: Is Interface Supersaturation a Plausible Primary Nucleation Mechanism?, Cryst. Growth Des., 2020, 20(11), 7276-7290, DOI: 10.1021/acs.cgd.0c00942.

60 C. E. Brennen, Cavitation and Bubble Dynamics, Oxford University Press, New York, 1995.

61 R. Prasad and S. V. Dalvi, Sonocrystallization: Monitoring and Controlling Crystallization Using Ultrasound, Chem. Eng. Sci., 2020, 226, 115911, DOI: 10.1016/j. ces.2020.115911.

62 J. Rodríguez-Rodríguez, A. Casado-Chacón and D. Fuster, Physics of Beer Tapping, Phys. Rev. Lett., 2014, 113(21), 214501, DOI: 10.1103/ PhysRevLett.113.214501.

63 E. Sanz, C. Vega, J. R. Espinosa, R. Caballero-Bernal, J. L. F. Abascal and C. Valeriani, Homogeneous Ice Nucleation at Moderate Supercooling from Molecular Simulation, J. Am. Chem. Soc., 2013, 135(40), 15008-15017, DOI: 10.1021/ ja4028814. 